\title{
COMERCIO MUSULMÁN VERSUS COMERCIO CRISTIANO: LA ACTIVIDAD DE LOS MERCADERES MUDÉJARES Y LA PRODUCCIÓN DE LAS ALJAMAS SARRACENAS. VALENCIA, PRIMERA MITAD DEL SIGLO XIV ${ }^{{ }^{*}}$.
}

\author{
Juan LeOnardo Soler Milla ${ }^{2 * *}$ \\ UniVERSITAT D'AlaCANT
}

\begin{abstract}
Resumen: El trabajo que se presenta corresponde a un análisis del peso de la economía musulmana en la articulación comercial valenciana durante la primera mitad del siglo XIV. Para ello se examinan dos procesos fundamentales, la funcionalidad de los mercaderes y comerciantes mudéjares en las redes de comercio mediterráneo y en el mercado de la ciudad de Valencia, así como la importancia de la producción agrícola andalusí, fundamentalmente de las comarcas de la Marina, para los hombres de negocio cristianos quienes concentran, acaparan y distribuyen estos productos enrolándolos en las rutas mercantiles internacionales.
\end{abstract}

Palabras clave: Valencia, primera mitad del siglo XIV, producción agrícola, alamín, comerciantes musulmanes, mercaderes cristianos, rutas mercantiles.

Abstract: This work matches up with an analysis of the weight of the moslem economy with regard to the commercial structuring in the city of Valencia during the first half of

\footnotetext{
1. ${ }^{*}$ El presente estudio forma parte de nuestro proyecto de tesis doctoral «Mercado y actividad comercial en Valencia durante el siglo XIV: rutas, mercaderes e intercambios», dirigido por J.V. Cabezuelo Pliego, profesor titular de Historia Medieval de la Universidad de Alicante, y financiado por la Generalitat Valenciana, que ha tenido uno de sus primeros resultados en el Trabajo de Investigación: Métodos comerciales y rutas mercantiles marítimas en Valencia durante la primera mitad del siglo XIV, Alicante. 2004.

2. ** Becario de Investigación de carácter predoctoral.
} 
the XIV century. For that, two fundamental process are both examined, the functionality of the mudéjar merchants and traders in the mediterranian commercial network and in the market of the city of Valencia, as well as the importance of the andalusian farming production, fundamentally on the regions of La Marina, for the christian businessmen who assemble, hoard and distribute these products putting them in the international commercial routes.

Keywords: Valencia, first half of the XIV century, farming production, alamín, moslem traders, christian merchants, commercial routes.

En el panorama historiográfico del Mudejarismo, las actividades económicas, en especial el comercio, ha sido uno de los ámbitos temáticos menos estudiados en comparación con las cuestiones fiscales, institucionales o propiamente sociales. En una reciente síntesis, J. Hinojosa realizaba un balance de la actividad mercantil mudéjar reseñando la importancia que tuvo este colectivo, o mejor dicho diversos individuos, en el comercio exterior destacando a su vez la vitalidad de las grandes familias de mercaderes de la morería de Valencia. Además, el citado autor subrayaba la participación de los mudéjares en el transporte fluvial, los guiajes o salvoconductos que propiciaban la movilidad de estos individuos incentivada por diferentes motivos, entre ellos los comerciales, las noticias derivadas de las exenciones fiscales junto a la permanencia modificada de los mercados, viva herencia de la época musulmana ${ }^{3}$.

En el caso valenciano, los mudéjares gozan de una vasta y rica tradición historiográfica que quizá necesitaría de un estudio de conjunto que ensamblara trabajos realizados con diferentes metodologías y, sobre todo, incorporara un amplia caudal documental, derivado del examen muy diversas fuentes, con el objetivo de asentar hipótesis y trazar nuevas perspectivas de análisis. En este sentido, el objetivo que nos proponemos durante estas páginas descansa en dos elementos de examen muy concretos e internamente imbricados, como son la actividad comercial de los mudéjares valencianos, sobre todo de la capital regnícola y Xàtiva, en pleno proceso de articulación del mercado por lo que respecta

3. Hinojosa Montalvo, J., Los mudéjares. La voz del Islam en la España Cristiana, II Vols. Teruel, 2002, pp. 220-227 del primer volumen. Respecto a los trabajos que versan sobre los temas referidos, véase para el transporte fluvial, en LEDESMA RuBio, Mª L., «Los mudéjares aragoneses y su aportación a la economía del reino. Estado actual de nuestros conocimientos y vías para su estudio», en IV Simposio Internacional de Estudios Mudéjares, Teruel, 1993, pp. 91-112. En cuanto a los aspectos fiscales que dejan huella de la actividad comercial; para el caso concreto de la Gobernación de Orihuela: Ferrer i Mallol, Mª T., Les aljames sarraines a la Governació d'Oriola en el segle XIV. Barcelona, 1988, pp. 145-154. Asimismo para los desplazamientos con carácter comercial de los mudéjares, véase los diversos trabajos de J. Guiral, $\mathrm{M}^{\mathrm{a}} \mathrm{T}$. Ferrer, J. Hinojosa, M. Ruzafa, Mª D. López Pérez o R. Salicrú que se citarán en notas posteriores. 
al complejo panorama de las transacciones que se producían en el mercado local en la Valencia de las primeras décadas del Trescientos; por otro, la producción de las aljamas que, desde muy pronto se canalizó al tráfico mercantil, analizando la función de las autoridades políticas musulmanas y el papel ejercido por los mercaderes cristianos. Considerando en ambos casos estos dos factores del análisis, mercaderes y producción mudéjar, en relación con su función y peso en la economía del país valenciano en la baja Edad Media. De esta forma se pretende integrar el estudio de las relaciones económicas de una minoría social -los mudéjares- en el marco amplio de la sociedad cristiana ${ }^{4}$. Hecho que en el examen de una actividad como el comercio, económica y dinámica por excelencia, guarda una relación sustancial a la hora de describir todo un complejo proceso de aseguración-adquisición de una mercancía y posterior puesta en comercialización y obtención de beneficios a través de su venta.

\section{REDES MERCANTILES: LOS MUDÉJARES EN EL MUNDO DE LAS TRANSACCIONES}

\section{a) Los mudéjares en la articulación del mercado}

En el entramado del mercado valenciano, donde aparecen numerosos comerciantes locales y del país, además de una destacada colonia de mercaderes de Perpiñán, Montpellier, Narbona, de la Corona castellana y por supuesto de catalanoaragoneses, sobre todo mallorquines y catalanes, comprando una variada gama de mercancías. Un mercado que comienza a ser inundado por paños del norte de Europa y sobre todo de procedencia occitana, además de la incipiente manufactura local, cereales de origen mediterráneo y regnícola, madera de proveniente de las serranías conquenses y turolenses, pieles, lanas y cueros magrebíes elaborados, productos del fértil agro valenciano y un sin fin de objetos más, en el que participan los mudéjares de forma activa. En las actas notariales de estas décadas que radiografían buena parte de estas transacciones y que señalan el carácter mercantil de la urbe, aparecen estos individuos inmiscuidos en las transacciones. En concreto vamos a focalizar nuestro interés en la función distribuidora de papel, recipientes de cerámica que se utilizarán como contenedores

\footnotetext{
4. Recientemente R. Salicrú ha llamado la atención sobre la necesidad de realizar estudios que reparen no sólo de forma exclusiva sobre el papel mercantil de las minorías etnicorreligiosas- musulmana y judía- sino también su relación con el grupo mercantil cristiano y, más específicamente, su función comercial en la ruta del Magreb en la baja Edad Media: R. SALicrú i Lluch, «Mudéjares y cristianos en el comercio con Berbería: quejas sobre favoritismo fiscal y acusaciones de colaboracionismo mudéjar, una reacción cristiana a la defensiva», en VII Simposio Internacional de Mudejarismo. De mudéjares a moriscos: una conversión forzada, Teruel, 1999, p. 299, nota 44.
} 
de vino, aceites y caldos además de otros productos. Por otro lado, también en la adquisición de paños y productos básicos para su abastecimiento.

Es así que importantes mudéjares setabenses acuden a la capital del reino a vender papel con notable éxito ${ }^{5}$. Por ejemplo, a comienzos de 1317 , Joan Docèse, mercader de Narbona realizaba dos compras de papel a Mafone Açabach, sarraceno de Xàtiva, por un valor de 19 libras y 10 sueldos y 62 libras y 16 sueldos respectivamente 6 . En estos mismos años, 1317-1318, tenemos algunas otras noticias de las operaciones de mudéjares setabenses, es el caso de Azmet Abdulmumil y su hijo Ali Abdulmumil, que realizan al menos durante este breve período de tiempo hasta tres ventas de la citada mercancía. Durante el mes de mayo de este mismo año, los mercaderes de Barcelona, Bernat de Arboret y Bernat Casa-sàgia, factor del primero, muy vinculados al tráfico mercantil exterior valenciano al fletar durante estos años algunas naves para mercadear en el Magreb, reconocían deber a estos musulmanes de Xàtiva, 50 libras y 10 sueldos ${ }^{7}$. Similar actuación tuvieron otros tantos mercaderes narboneses como Pere Arnand, Bernat Berenguer y una compañía muy destacada en el tráfico de paños entre Narbona y Valencia, caso los hermanos Arquejaire, que también se reconocía deudores de los Abduldumil por la adquisición de papel $^{8}$. Poco tiempo después, esta vez un pañero de Valencia, Andreu Parençós, al que hallamos con frecuencia en el tráfico terrestre pañero entre Valencia y Castilla, adquiría papel en otras dos ocasiones. En primer lugar, reconocía una deuda con Eximen de Font y Bernat Visquear, socios mercaderes de Valencia, y Mahomat Ubeyt, sarraceno de Xàtiva, de 72 libras y 8 sueldos por la adquisición de dicha mercancía ${ }^{9}$.

5. La significancia del papel setabense ha sido puesta manifiesta por diversos autores: MAdURELL I MARIMÓN, J.M., El paper a terres catalanes. Contribució a la seva història, II vols. Barcelona, 1972, INDICAR PP: R.I. Burns, Societat i documentació en el regne croat de València, vol. I, Valencia, 1988, pp. 228-242; VenTuRA, A., «Orígens del paper a Xàtiva» en La Imprenta valenciana, Valencia, 1990, pp. 123-142; Ferrer I MaLloL, $\mathrm{M}^{\mathrm{a}}$.T., «La moreria de Xàtiva (segles XIV-Xv)» en Xàtiva. Els Borgia. Una projecció europea, Xàtiva, 1995, vol. I, p. 198 (pp. 189-200); Garcia Marsilla, J.V., «El papel y la seda. Auge y caída dos industrias mudéjares en la X'ativa Medieval» en VII Simposio Internacional de Mudejarismo. Teruel, 1999, pp. 77-82.

6. Archivo del Reino de Valencia (A.R.V.), Protocolos Notariales (P. Not), nº 2792, Domingo Claramunt, (11-enero-1317) y (21-enero-1317). Alguna de estos intercambios que protagonizaba mercaderes occitanos fueron recogidos por Romestan, G., « Les marchands lenguadocians dans le royaume de Valence pendant la première moitié du XIVè siècle», en Bulletin Philologique et historique, année 1969, vol I, Paris, 1972, pp. 115-192. (reed., «Els mercaders llenguadocians en el regne de València durant la primera meitat del segle XIV», en A. Furió Diego. (ed.), València, un mercat medieval, Valencia, 1985, pp. 175-263, especialmente p. 223.

7. A.R.V. P. Not, No 2971, D. Claramunt, (15-mayo-1317)

8. En concreto Arnand compraba paños por un valor de 50 libras y 19 sueldos, vid. A.R.V. P. Not, No 2791, D. Claramunt, (10-mayo-1317), y los Arquejaire a través de Berenguer, 50 libras, 2 sueldos y 6 dineros: A.R.V. P. Not, No 2971, D. Claramunt (22-junio-1317).

9. A.R.V. P. Not, $\mathrm{N}^{\circ} 10.405$, D. Claramunt, (1-septiembre-1318). 
En segundo, efectuaba otra compra, esta vez a través de su hermano a Azmet Algatena, mercader musulmán de Xàtiva, pero que conmoraba en Valencia, por una cantidad de 51 libras y 10 sueldos $^{10}$. Otro documento nos desvela una interesante vinculación entre estos sarracenos setabenses, se trata de una procuración negociada por Ponç Gizmar, mercader valenciano y dos mercaderes mudéjares, uno de ellos el citado Azmet, para que en su nombre y el de Bonanat Manzecosa y Mahomat Algatena, salden deudas con otros comerciantes como los hermanos Arboreto y la familia Abduldumil, quizá por la venta de pape ${ }^{11}$. Por último, me gustaría destacar otra operación de la misma magnitud que las anteriores, esta vez datada en 1326, donde dos mercaderes narboneses compran papel a Maimó Fuster, este primero también ligado al comercio con el Magreb, y su socio Maimó Çaba, moros de Xàtiva por un valor de 115 libras y 11 sueldos ${ }^{12}$.

Sirvan estos datos para poder considerar que el tráfico de papel y la actividad de los mercaderes mudéjares setabenses fue muy intensa durante las primeras décadas del Trescientos ${ }^{13}$; actividad que se beneficiaba de una producción papelera todavía muy importante por parte de la morería de Xàtiva, por lo menos hasta la segunda mitad del siglo XIV, desde cuando irá progresivamente decreciendo ${ }^{14}$. Esta producción, además de destinarse a usos cancillerescos en la escrituración/ administración de la Corona de Aragón ${ }^{15}$, frecuentaba el mercado valenciano, haciéndose eco ello destacados mercaderes de la ciudad de Valencia y occitanos, que distribuían una variada gama de $\operatorname{productos}^{16}$. Papel que se configuraría quizá junto a la venta de purple cloth, como uno de las principales fuentes de ingreso

10. A.R.V. P. Not, $\mathrm{N}^{\mathrm{o}} 10.405$, D. Claramunt, (1-septiembre-1318).

11. A.R.V. P. Not, $N^{o} 10.405$, D. Claramunt, (1-septiembre-1318).

12. A.R.V. P. Not, $\mathrm{N}^{\mathrm{o}}$ 10.408, Aparici Lappart, (28-junio-1326).

13. Algunas referencias a décadas anteriores nos hacer ahondar en este idea como por ejemplo la existencia de un alfondec real en Valencia desde 1282 que, desde instancias reales, trataba de obtener el mayor beneficio con la venta de este producto; Garcia Marsilla, J.V., «El papel y la seda..., pp. 78-79.

14. Decaimiento señalado por todos los autores, en especial J.V. García Marsilla quien a través de las cuentas del Mestre Racional sobre el arrendamiento del impuesto que gravaba dicho producto (marxam del paper) para el siglo XV (1386-1500) y a través de algunos datos para décadas precedentes ha señalado tal decrecimiento, Garcia Marsilla, J.V., «El papel y la seda..., pp.79-80.

15. Hecho señalado por todos los autores, especialmente MAdurell i MARimón, J. M., El paper a terres catalanes. 2 Vols, Barcelona, 1973. Burns, R. I., Societat i documentació en el regne croat de València. Diplomatarium I. Introducció. Valencia, 1988, pp. 211-242.

16. Papel que salvo en la compras realizadas por los mercaderes narboneses, que distribuirían en sus mercados de origen, no podemos considerar que fuera una mercancía habitual en las redes mercantiles exteriores y ni mucho menos abundante al menos por los datos conocidos a través de las comandas y nòlits de la primera mitad del siglo XIV: Soler Milla, J.L., Métodos comerciales y rutas mercantiles maritimas, cit. Visiones más optimistas a este respecto; O'ConNOR, A.I.,, A forgotten community: the Mudejar aljama of Xàtiva, 1240-1327. Brill-Leiden-Boston. 2003, p. 99 («Their distribuition, especially in the case of paper, reached far away Christian and Islamic regions»); GARCIA Marsilla, J.V., «El papel y la seda..., p. 79. 
para la morería de Xàtiva por su buena aceptación e importancia en el mercado regnícola ${ }^{17}$.

En el caso de los recipientes cerámicos en forma de jarras asistimos durante el comienzo del Trescientos a una verdadera afluencia de mudéjares, fundamentalmente de Paterna y Manises, a la ciudad de Valencia para vender tal mercancía e intercambiarla muchas veces con mercaderes locales o de Narbona a cambio de paños. En algún caso también se producen compras anticipadas y en la mayoría de ellos se especifica muy bien las medidas del recipiente y su funcionalidad. Se trata asimismo de unas transacciones de índole local, los sarracenos libraban tal mercancía (botas, obra de la tierra) a los mercaderes que estos utilizaban para la exportación de otros productos ${ }^{18}$. Existe también alguna noticia de exportación de cerámica dorada a tierras occitanas ${ }^{19}$.

Además, también es bastante frecuente encontrar a sarracenos las actas notariales reconociéndose deudores por la compra de cueros, madera, materias tintóreas, paños, ganado, grano, tierras y propiedad, por citar algunas, sin embargo su actividad fue bastante modesta, salvo en los productos arriba descritos, en relación a mercaderes valencianos y en menor medida occitanos y cataloaragoneses, blanquers, fusters, drapers y vecinos de la ciudad del Turia que capitalizaban las transacciones del mercado ciudadano ${ }^{20}$.

17. A esta conclusión llega, O’Connor, A.I.,, A forgotten community..., p. 81 y 98-99, al considerar el peso de estas dos manufacturas en el conjunto de la economía del reino de Valencia, sin embargo no ofrece datos acerca de las transacciones y sigue lo establecido por R.I. Burns, vid. Supra. Asimismo M ${ }^{\mathrm{a}}$.T. Ferrer se ha hecho eco de las transacciones de los mudéjares setabenses en Valencia: «A l'interior del regne, consta que el paperaires acudien a vendre a València con regularitat», en FERRER I MALlol, M ${ }^{\mathrm{a}}$.T., «La moreria de Xàtiva..., p. 200. El caso de la seda setabense es el contrario al papel irá ganado importancia a través del tiempo constituyéndose en el Cuatrocientos una materia prima relevante para la manufactura local valenciana: García MarsiLla, J.V., «El papel y la seda..., p. 81-82.

18. Los ejemplos son numerosos, para no redundar en descripciones de estas compraventas y dada las restricciones de espacio para elaborar este trabajo, remitimos a la obra de P. López que recoge un buen número de las compraventas de cerámica de Paterna y Manises halladas en los protocolos notariales: LóPEz ELuM, P., Los orígenes de la cerámica de Manises y Paterna (1285-1335), Manises, 1985.

19. Romestan, G., «Els mercaders llenguadocians en el regne de València..., p. 222, que cita un contrato de compra de Ramon Roch, mercader de Narbona a cuatro sarracenos de Manises a cambio un paño de color morado. F. Amigues repara, a través de los registros de la lezda de Colliure y el anterior dato sobre el comercio de esta mercancía entre Valencia y el Languedoc-Rosellon en esta época: AmiguEs, F., «Las importaciones de cerámicas doradas valencianas de los talleres de Paterna en el Languedoc-Rosellón», en VV. AA, La cerámica de Paterna. Reflejos del Mediterráneo. Valencia, 2002, pp. 60-61 y 65-66.

20. En este sentido la minoría judía también se puede considerar como dinamizadora en el mercado local de principios del Trescientos, en las actas notariales participan de forma notable en el crédito y en las compraventas anticipadas (vino y cereales): García Marsilla, J.V., «Puresa i negoci. El paper del jueus en la producció i comercialització de queviures en la Corona d'Aragó» en Revista d'Història Medieval, 4, 101-125; Idem, Vivir a crédito en la Valencia bajomedieval. De los orígenes del censal al endeudamiento del municipio. Valencia. 2002, pp. 85-100. 


\section{b) Los mudéjares en el tráfico exterior}

Mayor tratamiento es el que la historiografía ha reparado sobre los musulmanes valencianos dentro del tráfico mercantil internacional. Desde 1982, cuando J. Guiral realizó un balance de la participación de las minorías musulmana y judía en el comercio hasta la actualidad, diversos autores han tomado como elementos de análisis los guiajes o salvoconductos otorgados por las autoridades cristianas a los mudéjares para comerciar principalmente en los mercados islámicos (reino nazarí de Granada y el norte de África), en la baja Edad Media, sobre todo en la centuria cuatrocentista o a través de otros tipos documentales para analizar esta actividad $^{21}$.

Durante este primera mitad del Trescientos, en la documentación conservadaza también ha quedado huellas de estas licencias (guiatges). En concreto, en el Archivo del Reino de Valencia existe un registro de bailía (n ${ }^{\circ} 1142$ bis), datado en 1335-1336, que contiene casi una veintena de licencias concedidas a mudéjares de la morería de Valencia y de otras aljamas, fundamentalmente de las comarcas de la Marina, para comerciar en tierras musulmanas. Se trata de una documentación que ya fue recogida y analizada por J. Hinojosa y M ${ }^{a}$. D. López, insertándola, esta última, en un examen más amplio que consistía en la participación de las minorías sociales y religiosas en el tráfico de la Corona de Aragón con el Magreb durante el siglo XIV ${ }^{22}$.

A pesar de la parcialidad de este tipo documental, su importancia radicaba al menos en reflejar desde una época relativamente temprana las conexiones mercantiles entre Valencia y el territorio nazarí y sobre todo magrebí. Un análisis detallado de esta documentación nos proporciona una información muy precisa que apunta a señalar el beneficiario de la licencia (profesión y origen), el destino del viaje, en ocasiones genéricamente Berbería, la razón del salvoconducto, en muchas de ellas detallada (per rahó de mercadería) y raramente se señala el tipo de mercancía. De esta forma, conocemos una serie de mudéjares de la

21. Guiral Hadziossif, J., «L'apport des communautés juives et musulmanes au commerce maritime de Valence au XVè siécle», en Deuxième Colloque International d'Histoire : Économies méditerranéennes : équilibres et intercomunications. XIIIè-XIVè siècles», Atenas, 1985, pp. 461-474 (reed. «L'aportació de les comunitats jueva i musulmana al comerç maritim de Vàlencia al segle Xv» en Afers, 5/6, (1987), pp. 33-46). Así como algunos otros trabajos de RuZAFA GARCíA, M., «Los mudéjares en el desarrollo mercantil valenciano del Cuatrocientos», en Revista d'Història Medieval, 2, Valencia, 1991, pp. 179-189; Idem, «Los operadores económicos de la morería de Valencia», en IV Simposio Internacional de Mudejarismo, Teruel, 1993, pp. 247-260; Idem, «Ali Xupió, senyor de la moreria de Valencia» en, VV.AA., L'Univers del prohoms, Valencia, 1995, pp. 137-173. También hay constancia de licencia a mudéjares setabenses para comerciar en territorios norteafricanos: FerRer i MALlol, Ma.T., «La morería de Xàtiva..., p. 200.

22. Hinojosa Montalvo, J., Documentación medieval alicantina en el Archivo del reino de Valencia, Alicante, 1985, pp. 23-24, donde se regestan las que atañen a la actual provincia de Alicante; LóPEz Pérez, Ma .D., La corona de Aragón y el Magreb en el siglo XIV (1331-1410), Barcelona, pp. 318-327. 
morería de Valencia: Abraham, hijo de Abd Allah Zorzo, tintorero, Çaat, hijo de Jusuf Pretxes, Muhammad, platero, Niça Alfulfel, Muhammad Ibn Gamin, Hamet Bocorn, Ali ibn Hamet Abd-Aziz, Bauqer Albatur, que se dirigen a los puertos de Berbería a comerciar durante los meses de marzo a diciembre del año $1335^{23}$. Asimismo también algunos mudéjares de la Marina, Abd al-Salim, probablemente de Benissa, Hamet Hami, vecino de la alquería de Canor, Hamet Alaiemi y Hamet Apoloni, vecinos de Calpe, Hamet Azani, de Pedreguer, Maimo Xalici y Maimó Dechi, musulmanes de Exalb, Abu Hasan, de Ondara, Gena Algalifa, de Murla, Cilim Addux procedente de Murta, alquería del término de Calpe, Alí Abezqueri, de Benidulenyes. Todos ellos se dirigen a los enclaves de Alcudia, Orán, Argel, Tedelis, Bugía, y en una ocasión a Almería, con idénticos fines desde mediados de $1335^{24}$. Por último se señala, como se ha referido, el tipo de mercancías: higos y cleda (materia tintórea).

A su vez hay constancia de otras noticias aisladas sobre la participación de mudéjares en el tráfico exterior a mediados del Trescientos, como el flete que concertaron Alí Facal y Alí Alfofell, mercaderes de Valencia, con Pere Figuera, mercader de Mallorca, para transportar unas mercancías a Bugía a fines del verano de 1343 y que tuvo un final desgraciado por cuanto el mallorquín quedó apresado en tierras bugiotas y los valencianos huyeron ${ }^{25}$. La comanda mercantil que negociaron Ali Abengalip, cadí de Ondara, y Ali Axeix, sarraceno de Murla, con Joan Gay, mercader de la capital del reino, y su procurador en Denia, depositándoles una cantidad indeterminada de quintales de higos, pasas, miel y otras mercancías, valoradas en 85 libras, que se destinaron a $\mathrm{Túnez}^{26}$. O la requisición efectuada por Nicola de Rustugo, patrón genovés de Mallorca a Alhaig Cabbet,

23. A.R.V. Bailía, No 1142, f. 2-v-3-r (29-marzo-1335), f. 4-r (3-abril-1335), f. 12-r-v (4-mayo-1335), f. 40-v 14-octubre-1335),f. 45-r (13-noviembre-1335), f. 46-r (13-noviembre-1335), f. 48-v-49-r (11-diciembre-1335), respectivamente. Cit. LóPez PÉrez, Mª.D, La corona de Aragón y el Magreb..., pp. 320-321. También esta última autora recoge una licencia a Maimó Fuster, sarraceno de Valencia, quien junto a otros dos mercaderes de Valencia, obtienen permiso para comerciar en Bugía y Túnez en marzo de 1343, finalizada la Guerra del Estrecho, vid. Ibidem, p. 93.

24. A.R.V. Bailía, No 1142, f.10-r (26-abril-1335), f.12-r (5-mayo-1335), f.47-v (29-noviembre-1335), f.48r (1-diciembre-1335), f.48-v (8-diciembre-1335), f.54-v (13-enero-1336), f.53-v (8-enero-1336), f. 61-r (25-febrero-1336), f. 61-r (25-febrero-1336), respectivamente. Vid. Hinojosa Montalvo, J., Documentación medieval alicantina..., pp. 23-24; LóPez PéRez, Ma.D., La corona de Aragón y el Magreb..., pp. 321-323. Licencias que se generalizaran durante el siglo XV, teniendo todas ellas también como destino los puertos de Berbería: 118 guiajes entre 1421-1431, 386 desde 1452 a 1465 y más de 870 para los años 1465-1491, cf. Guiral Hadziossif, J., «La apport des comunitées..., pp. 464-465 y 473-474.

25. Archivo del Reino de Mallorca, Lletres Comunes, $N^{\circ}$ 4, (6-9-1343).

26. A.R.V. Justicia Civil, $N^{\circ} 102$, (26-4-1345). Dicha operación acarreó una disputa entre las partes ya que el mercader cristiano no llegó a un acuerdo con los sarracenos a la hora de devolverles las cantidades invertidas y beneficios, hecho que llevo al justicia a asignar a dos árbitros para determinar el el contrato efectuado. 
moro de Valencia, que había fletado la coca del primero para traer trigo, cebada y cotón procedente del Magreb en octubre de 1348. Transcurridos unos meses el mudéjar no había satisfecho todo las condiciones del nòlit, lo cual condujo a una disputa entre ambos y la necesidad de la determinación de dos árbitros familiarizados en el arte de la mercadería ${ }^{27}$.

Sin restar importancia a estos datos, que nos ejemplifican una parte de los intercambios con el Norte de África durante la primera mitad del siglo XIV y por otro lado nos muestran la relativa prontitud de estas licencias que se generalizarán a fines del citado siglo, la documentación notarial y judicial nos revela que en estas décadas la ruta entre la ciudad de Valencia y el Magreb estaba muy polarizada por la actividad de los mercaderes cristianos valencianos y en menor medida por la participación del comerciantes de la propia corona catalanoaragonesa- mallorquines y barceloneses ${ }^{28}$. Entre estos dos territorios, Valencia-Magreb, comienzan a configurarse unos estrechos vínculos al hilo de la apertura comercial que la ciudad de Valencia estaba desarrollando por las diferentes áreas del Mediterráneo Occidental (mercados sículo-sardo, isla de Mallorca, puertos catalanes y occitanos, además del Norte de África y la Andalucía atlántica) caracterizados por intensa actividad exportadora de productos del agro y en menor volumen manufacturas a cambio, a su vez, de materias primas, cereales, metales preciosos y otros productos básicos para su economía ${ }^{29}$. En este sentido, la ruta

27. A.R.V. Justicia Civil, $\mathrm{N}^{\circ} 128,(19-10-1348)$. Una vez fijadas las cantidades a satisfacer entre ambas partes, dispuestas por Guillem Abelló y Pascual Maçana, mercaderes de Valencia, el citado Alhaig sugirió al justicia que no se entrometiera en estos asuntos porque se trataba «de negocis dela mar», pidiendo la determinación de los «cónsols de la mar»; desgraciadamente no hemos hallado el final de la disputa y no sabemos con certeza si esta actuación era un procedimiento para demorar su deuda o bien un recurso de rechazo a la disposición de los jueces asignados.

28. Un primer acercamiento a estos vínculos económicos entre el Magreb y la Corona de Aragón a partir del observatorio valenciano en el Trescientos lo hemos realizado en SOLER MiLLA, J.L., «Relaciones comerciales entre Valencia y el Norte de África en la primera mitad del siglo XIV», en prensa. Remito a este trabajo para acercarse a la extensa bibliografía sobre relaciones económicas entre la Corona de Aragón y el Magreb en la Baja Edad Media. Por otro lado la dominación cristiana de la ruta magrebí puesta de relieve para el mismo espacio-Valencia-y por extensión la Corona de Aragón, para décadas posteriores a las examinadas en este trabajo (segunda mitad del siglo XIV y siglo XV) por. LóPEz Pérez, Ma . D., La corona de Aragón y el Magreb..., pp. 317-346 y 853. SALICRú I Lluch, R., «La Corona de Aragón y Génova en la Granada del siglo XV», en Mª T. Ferrer I Mallol., D. Coulon. (eds.), L'expansió catalana a la Mediterrània a la Baixa Edat Mitjana, Barcelona, 1999, pp. 121-144; Ídem, «La presència comercial catalanoaragonesa al sultanat de Granada durant el regnat de Alfons el Magnánim» en XVI Congreso de la Corona de Aragón, Nápoles, 2000, pp. 1173-2000; Ídem, «Mudéjares y cristianos en el comercio con Berbería..., p. 299-300, nota 244: donde se hace eco de las impresiones de M.D. Meyerson que destacaba la escasa incidencia de los mudéjares en el comercio internacional.

29. Una visión clásica de las fases de la actividad comercial valenciana durante la baja Edad Media en IRADIEL Murugarren, P., «Valencia y la expansión mediterránea de la Corona de Aragón», en La Corona d'Aragó: El regne de València en l'expansió medieterrània (1238-1492), Valencia, 1991. pp. 80-88, (reed. en D. Abulafia., B. Garí. (dirs.), En las costas del Mediterráneo occidental. Las ciudades de la Península Ibérica 
norteafricana comprende unos intercambios definidos por la importación de distintos tipos de lana, lino, cueros, cera, esclavos, oro y cereales y una exportación desde territorio regnícola de variados frutos de la agricultura del reino como las uvas pasas, higos secos, almendras, avellanas, algarrobas, arroz junto a vino, junco, alheña, aceite, jabón, materias tintóreas y sal de las salinas meridionales del país. Unas redes mercantiles articuladas por mercaderes locales que se sirven de una flota comercial muy ligada también a patrones del país y cataloaragonses que se aprovechan de una red de cargaderos que jalonan la costa valenciana para embarcar las producciones -fundamentalmente uvas pasas e higos- que estos pequeños puertos concentran de las fértiles comarcas interiores ${ }^{30}$.

El análisis conjunto de diversos registros documentales, públicos (bailía) y privados (notarial), nos ofrece una visión más rica y variada de los factores que conforman la actividad mercantil de las que participa el componente económicoproductivo y social de los mudéjares. El peso de la población mudéjar durante el Trescientos fue muy notable y su función en el complejo proceso de articulación del mercado regnícola y desarrollo de los circuitos exteriores no debe desdeñarse. Sin embargo, desde la propia regulación política, real y municipal, de los variados ámbitos de la vida (obsérvese la economía en primer grado), así como de la misma funcionalidad que un grupo social- los mudéjares- puede ocupar dentro de un poder -cristiano- que organiza la actividad económica en una dirección y con un interés muy determinado, se puede ahondar en el argumento de que las transacciones que protagonizaban estos mercaderes mudéjares o la producción que los mercaderes cristianos intentaron concentrar y acaparar de las aljamas, constituía uno de los escasos recursos que estos individuos tenían para cubrir sus necesidades en algunos casos, la mayor parte, y en otros para generar

y del reino de Mallorca y el comercio mediterráneo en la Edad Media, Barcelona, 1996, pp. 155-169); y exclusivamente para el siglo XIV: RuBIo VelA, A., «El segle XIV», en Història del País Valencià, coord. por E. Belenguer Cebrià, vol. II, Barcelona, 1989, pp. 181-185 y 241-246. De forma más reciente, E., CruseLLES Gómez, Los mercaderes de Valencia en la Edad Media (1380-1450), Lérida, 2001, pp. 23-36; GARCíA Marsilla, J.V., Vivir a crédito en la Valencia bajomedieval..., pp. 19-34; IguAl Luis, D., «Política y Economía durante la Baja Edad Media. El papel de la Monarquía en el comercio exterior valenciano», en J.A. BARrio BARrio, Los cimientos del Estado en la Edad Media. Cancillerías, notariado y privilegios reales en la construcción del Estado en la Edad Media. Alicante, 2004, pp. 251-253, (249-278). Más específicamente para las primeras décadas del Trescientos: Soler Milla, J. L., Métodos comerciales y rutas mercantiles marítimas..., op. cit. Una bibliografía más amplia y una visión sintética acerca de las rutas mercantiles frecuentas por mercaderes de Valencia se puede consultar en IGUAL LuIs, D., «Itinerarios comerciales en el espacio meridional mediterráneo de la Baja Edad Media», en XXVII Semana de Estudios Medievales de Estella «Itinerarios Medievales e identidad hispánica», Pamplona, 2001, pp. 113-158.

30. De forma especial para las tierras oriolanas: Soler MiLlA, J.L., «La actividad comercial en la gobernación de Orihuela durante la baja Edad Media. Un balance» en J.F., JimÉnez AlcÁzAr, J. A., EiroA Rodríguez, J.L., Soler Milla. (eds.), Actas del II Simposio de Jóvenes Medievalistas, Lorca 2004, Lorca (Murcia) 2006, pp. 223-240. 
desarrollo y liquidez de sus haciendas. Además de servir de forma esencial para contribuir a edificar beneficios que sólo de forma individual aprovecharán ciertos individuos. A la luz de los datos exhumados desde las fuentes cristianas circunscritas a las primeras décadas del Trescientos, no podemos destacar el protagonismo de familias de mercaderes mudéjares que tuvieran una trayectoria relevante en el tráfico exterior, como si lo poseerán algunos linajes (Ripoll, Bellvis y sobre todo Xupió) para el Cuatrocientos ${ }^{31}$. Y sí es necesario considerar la presencia de sarracenos de una importante aljama de Xàtiva junto con los de la modesta morería de Valencia y de otras pequeñas aljamas del reino que dinamizan, sólo de forma local, los intercambios ${ }^{32}$. Diferente reflexión nos produce, como se ha vislumbrado, la producción agrícola mudéjar que reseñaremos a continuación a través de unos ejemplos muy concretos.

\section{ACAPARAMIENTO DE LA PRODUCCIÓN SARRACENA Y COMERCIALIZACIÓN CRISTIANA: LA GENERACIÓN DE UN DESTACADO BENEFICIO}

A través de lo anteriormente descrito hemos podido comprobar que los productos del agro eran en esencia una de las partes más relevantes del volumen que las naves valencianas destinaban al mercado exterior. Por tanto, nuestro interés es profundizar en esta producción agrícola, sobre todo uvas pasas e higos, que dominaban buena parte del tráfico y que eran de claro origen musulmán (estas

31. Guiral Hadziossif, J., «La apport des comunitées..., pp. 465-466; Barceló Torres, Mª C., Minorías islámicas en el País Valenciano. Historia y dialecto. Valencia. 1984, pp. 74-77. RuZAfa García, M., «Ali Xupió..., pàssim. Como ha referido R. Salicrú se trataría de una pocas familias de mudéjares de una vitalidad reseñable pero que su importancia habría que relacionarla con la actividad de otra minoría como la judía y sobre todo el grupo mercantil cristiano: SAlicrú i Lluch, R., «Mudéjares y cristianos en el comercio con Berbería...., p. 299. Una reflexión en otro plano sería si estas familias o grupos de mercaderes se pueden considerar oligarquías o elites dentro de la sociedad mudéjar sin descuidar, otra vez de nuevo, su relación con la elite cristiana; véase MolÉnAt, J.P., «L'Élite Mudéjare dans la Péninsule Ibérique Médievale», en F. Themudo Barata (ed.), Elites e redes clientelares na Idade Média. Problemas Metodológicos. Lisboa, 2001, pp. 45-53.

32. De hecho, salvo en los guiajes referidos (notas 22 y 23) en los centenares de contratos, nòlits y comandas, negociadas en Valencia durante la primera mitad del siglo XIV (1309-1338) procedentes de los protocolos notariales y algunas series del Justicia, la actividad mudéjar fletando embarcaciones e invirtiendo capital en forma de comandas es bastante modesta (véase algunos ejemplos supra, notas 30, 31 y 32). Los mercaderes judíos sólo ocasionalmente son documentados en dos fletes, uno a Mallorca y otro al Norte de África. Vid. Soler Milla, J.L., Métodos comerciales..., op, cit; Idem, «Relaciones comerciales entre Valencia y el Norte de Africa..., op, cit. Su función, como se ha referido, quedaría circunscrita al mercado local: GARCíA MARSILlA, J.V., Vivir a crédito..., p. 97. Muy diferente es su actividad en Mallorca donde tiene una importancia destacada en la ruta norteafricana: Ma . D. LóPez PÉrez, La Corona de Aragón y el Magreb..., pp. 354-384; Tudela Villalonga L., Maíz Chacón, J., «Els mercaders jueus mallorquins a meitat del segle XIV», en XVIII Congreso de Historia de la Corona de Aragón, Universitat de València - Fundació Jaume II el Just, Valencia, 2005, pp. 1129-1148. 
últimas conservan su etimología árabe en la documentación -atzebib-) ${ }^{33}$. Productos que, desde tiempos anteriores, fueron intercambiados por los mercaderes musulmanes como se deduce a través de las descripciones de los geógrafos andalusíes, que se continuará realizando décadas inmediatas a la conquista cristiana de Sharq al-Andalus y que se consolidará en los siglos bajomedievales ${ }^{34}$.

Asimismo, y a tenor de los datos conocidos, paulatinamente más ricos, la producción de las aljamas sarracenas desde décadas posteriores a la conquista cristiana comienza a ser canalizada hacia los mercados exteriores. Es el caso de las aljamas de las montañas de Denia, quienes, según J. Torró, desde la segunda mitad del Doscientos comercializaban los higos secos y pasas como principal fuente de ingreso de plata $^{35}$. El proceso de venta de estas mercancías por parte de la aljama es más desconocido, en opinión del citado autor, serían los mercaderes quienes adquirían estos productos en el puerto de Denia y los distribuirían en las redes comerciales del Mediterráneo Occidental, sobre todo en el Magreb,

33. Las descripciones de los geógrafos andalusíes-al-Idrisi, Ibn Said al Magribi, al-Yaqub- refiriendo la riquiza del agro meridional Sharq al-Andalus son abundantes. Cf: Epalza Ferrer, M., «Estudio del texto de al Idrisi sobre Alicante», en Sharq al-Andalus, Estudios Árabes, 2, Alicante, 1985; Idem, "Costas alicantinas y costas magrebíes: el espacio marítimo musulmán según los textos árabes», en Sharq al-Andalus, Estudios Árabes, 3, Alicante, 1986, p. 30; Gamal Abd Al-Karim, «La España Musulmana en la obra de Yaqut (s. XII-XIII). Repertorio enciclopédico de ciudades, castillos y lugares de Al-Andalus, extraído de Muyam albuldan (Diccionario de los países)», en Cuadernos de Historia de Islam, 6, Granada, p. 88.

34. Tal mercancía es objeto de un intenso intercambio en los mercados mediterráneos desde época musulmana, véase Epalza Ferrer, M., «Estudio del texto de al Idrisi sobre Alicante», en Sharq al-Andalus, Estudios Árabes, 2, Alicante, 1985, pp. 224-227; este geógrafo musulmán señalaba la riqueza de las tierras alicantinas en estos frutos así como el puerto de Alicante como salida natural para su posterior comercialización; Constable, O.R, Comercio y comerciantes en la España musulmana. La reordenación comercial de la península ibérica del 900 al 1500, Barcelona, 1996, p. 250; y cristiana: Gual CAMAREnA, M, Vocabulario del comercio medieval. Colección de aranceles aduaneros de la Corona de Aragón (s. XIII y XIV), Barcelona, 1976, docs. $\mathrm{n}^{\circ} .3,4,6,8,9$, y 12, donde recoge la tarifa que se estimaba para este producto en el pago de las lezdas de Valencia, Alcira, Tortosa y Colliure; J. Torró I ABAD, El naixement d'una colonia. Dominació $i$ resistencia a la frontera valenciana (1238-1276), Valencia, 1999, pp. 175-185 y 228-230; FERRER i MALLOL, $\mathrm{M}^{\mathrm{a}}$. T., «Figues, panses, fruita seca i torrons», en La Mediterránia, àrea de convergencia de sistemas alimentaris (segles V-XVIII), XIV Jornades d'Estudis Histórics Locals, Palma de Mallorca, 1996, pp. 191-208, e IDEM., «Fruita seca, fruita aissecada, una especialitat del àrea económica catalano-valenciana-balear», en Anuario de Estudios Medievales, 31/2, Barcelona, 2002, pp. 883-943, López Pérez, Ma . D., La Corona de Aragón y el Magreb..., p. 570-573. Para el siglo XV alicantino algunos trabajos de carácter general de José Hinojosa y para un caso concreto de las tierras meridionales que gozaron de una producción excelente; Hinojosa Montalvo, J., Textos para la Historia de Alicante. Historia Medieval., Alicante, 1990, doc. 144, p. 293; Barrio Barrio J. A., Cabezuelo Pliego, J.V., «Rentas y derechos señoriales de las morerías del valle de Elda a finales del siglo XV», en VII Simposio Internacional de Mudejarismo. Teruel, 1999, p. 43-53; Soler Milla, J.L., «La actividad comercial en la gobernación de Orihuela..., 229-230; de forma especial para la Valencia de inicios del Trescientos: Idem, «Relaciones comerciales entre Valencia y el Norte de Africa..., op. cit.

35. Torró i AbAd, J., El naixemnet d’una colonia..., p. 228. 
donde adquirían dicha moneda ${ }^{36}$. Si centramos el análisis en las comarcas de la Marina Baja, J.V. Cabezuelo también señala que desde fines de la segunda mitad del siglo xIII, barqueros, patrones y mercaderes de Valencia, acudían a los embarcaderos de Calpe y Altea a nutrirse de los frutos de las aljamas de estas comarcas, principalmente higos y uvas pasas, que a su vez se comercializan en los circuitos mercantiles mediterráneos, destacando el mercado mallorquín, los puertos occitanos y el Magreb centro-oriental ${ }^{37}$. Asimismo, tampoco conocemos los mecanismos de venta y contratación de las aljamas sarracenas con los mercaderes cristianos, únicamente para el caso de las Marinas, la pronta inserción en el mercado de esta producción agrícola íntimamente relacionada con el modelo de agricultura de tradición islámica.

A través de las estipulaciones que se analizan en este estudio y que también versan sobre las aljamas de la Marina Alta en estas primeras décadas del Trescientos, la venta de la producción de dichas instituciones fue efectuada directamente por parte de los alamines, y en algún caso acompañado de otros individuos de estas aljamas, a mercaderes cristianos de la capital del reino ${ }^{38}$. Acuerdos registrados ante notario y que consistían en la venta anticipada de una mercancía que se debía depositar en los cargaderos de estas comarcas, principalmente Denia, pero no de forma exclusiva al funcionar ya en estas décadas otros embarcaderos de entidad menor, a cambio de una cantidad fijada y estipulada ${ }^{39}$. Si bien, estos contratos nos proporcionan una información muy precisa, a través de ellos también podemos extraer algunos otros datos que vehiculan un análisis mayor por

36. Acerca de la venta de la producción ejercida por la aljamas valencianas, J. Torró indica que «No és factible, per ara, determinar la forma exacta amb què procedía cada una de les aljames autònomes del regne en aquest assumpte...», para describir posteriormente la última fase del proceso de venta de las aljamas de la Marina Alta, esto es, la entrega de la mercancía en el puerto de Denia, Ibidem, p. 228.

37. Gracias al proceso que el baile general de Valencia incoó en el verano de 1317 para conocer los usos y derechos de los cargaderos de Calpe y Altea, tenemos acceso a esta información que revela la participación de al menos unos cuarenta individuos que comparecen como testigos y otros tantos referidos por estos mismos, quienes utilizaron estos embarcaderos con fines comerciales; todo ello en CABezuelo Pliego, J.V., «Comercio y puertos comerciales en el señorío valencianos en el tránsito del siglo XIII al XIV», en prensa. Agradezco al profesor J.V. Cabezuelo haberme facilitado el texto original para elaborar este trabajo.

38. Además del papel de los alamines existen otras noticias que destacan la importancia de las autoridades sarracenas, en particular en la Marina Alta, en los contratos con los mercaderes cristianos como la comanda mercantil negociada por el qadi de Ondara. Véase un ejemplo en este mismo estudio: nota 31.

39. También a fines de la baja Edad Media comerciantes de la capital y sobre todo las grandes compañías italianas y alemanas, unas veces asociados a mercaderes genoveses, sieneses, franceses y castellanos adquieren higos y pasas de la Gobernación de Orihuela (sobre todo Valle de Elda y Villajoyosa) y de las comarcas de la Marina. J. Guiral sugiere que unas veces forma las transacciones se hacían de forma directa («la nobleza local vende directamente sus cosechas a los comerciantes») y otras no («encarguen a un comerciante de la tierra que le haga de intermediario»): Guiral Hadziossif, J., Valencia, puerto mediterráneo en el siglo XV (1410-1525), Valencia, 1989, pp. 415-419, las citas en pp. 416 y 418 respectivamente. 
cuanto revelan en buen grado todo el proceso mercantil; aseguración-adquisición de una mercancía por parte de un mercader, depósito en un enclave marítimo a cargo de los productores o bien un representante (alamín) y recogida por parte de las naves fletadas a su vez por estos mercaderes para su realizar su posterior distribución. En este sentido tenemos que reflexionar sobre varios aspectos; en primer lugar la figura del alamín y su jurisdicción sobre las actividades económicas. En segundo, la importancia de estas mercancías para destinarlas al mercado, de ahí que relevantes mercaderes de la Valencia de la primera mitad del siglo XIV movilicen recursos para hacerse con seguridad con mercancías como las pasas e higos secos además de otros casos conocidos como madera, vino o cereal. Y por último, la pronta inserción de estos productos en los mercados occidentales al tener una acogida exitosa por parte de futuros consumidores y sobre todo para los distribuidores ya que en todo el proceso comercial el precio de la mercancía se incrementará notablemente.

La figura del alamín dentro del complejo institucional de las aljamas mudéjares goza de un amplio caudal de datos en diferentes dominios políticos y jurisdicciones, además de una considerable reflexión historiográfica ${ }^{40}$. La función ejercida por el alamín en las aljamas sarracenas bajo domino cristiano tuvo unas competencias muy determinadas que varían según jurisdicción (real, señorial) y territorios. Esta figura de claro origen musulmán (amín) tuvo una función menor en época musulmana que mudéjar, al menos por lo conocido hasta el momento. Sus atribuciones se extendían en el plano económico al convertirse en oficial de aduanas o jefe de un grupo comercial y en época omeya como funcionario fis$\mathrm{cal}^{41}$. Atribuciones que durante período mudéjar incrementará de forma notable

40. Véase entre los diversos estudios: Gual Camarena, M., «Mudéjares valencianos. Aportaciones para su estudios», en Saitabi, VII, 1949, pp. 165-199; Piles Ros, L., «La situación social de los moros de realengo en la Valencia del siglo XV» en Estudios de Historia Social de España, I, 1949, pp. 225-274; RoCA TRAVER F., «Un siglo de vida mudéjar en la Valencia bajomedieval (1238-1338)», en Estudios de la Edad Media de la Corona de Aragón, V, 1952, pp. 115-208; Basáñez Villaluenga, Mª B., La aljama sarracena de Huesca en el siglo XIV. C.S.I.C., Barcelona, 1989, pp. 15-23; R.I. BuRns, L'Islam sota el croats, Ed. Tres i Quatre, 1990, Vol. I, pp. 346-361 y Vol. II, pp. 138-146; J. Mutge ViVes, L'aljama sarraina de Lleida al segle XIV. Aproximació a la seva història, C.I.S.C, Barcelona, 1992, pp. 22-23 y 23-37; Febrer Romaguera, M.V., «La administración económica de las aljamas mudéjares valencianas a través del estudio del oficio del alamin», en IV Simposio Internacional de Mudejarismo, Teruel, 1993, pp. 261-280; TorRó I ABAD, J., El naixement d'una colonia..., p. 233-234; Ortega, P., Musulmanes en Cataluña. Las comunidades musulmanes de las encomiendas templarias y hospitalarias de Ascó y Miravet (siglos XII-XIV), C.S.I.C. Barcelona, 2000, pp. 127-135. Boswell, J. The royal treasure: muslim communities under the Crown of Aragon in the fourteenth century. Yale. 1977, p. 89. MonJo, M., Sarrains sota el domini feudal. La baronia d'Aitona al segle XV, Lleida, 2004, pp. 49-50.

41. Chalmeta, P., El señor del zoco en España: Edades Media y Moderna. Contribución al estudio de la historia del mercado. Madrid, 1973. Véase las diferentes funciones en noticias recogidas en las páginas 353-609. 
al considerársele una figura clave en el entramado político junto al cadí, almotacén y consejo de los viejos (jurados). El alamín mantendrá sus competencias en materia fiscal y se convertirá, en palabras de Burns, en una figura equiparable con el baile ${ }^{42}$.

En el caso valenciano, M.V. Febrer ha realizado un análisis de las figura del alamín en el que ofrece numerosos datos acerca de la función de dicho cargo en las diversas aljamas del reino de Valencia. Las funciones de este individuo, como no podía ser de otra forma, tratan cuestiones administrativas y judiciales; convocan las sesiones de las aljamas y las presiden, representan los intereses de la administración real o señorial, defienden y administran los bienes y rentas de la aljama y señores además de comprender facultades jurisdiccionales, jurisdicción civil sobre mudéjares que poseían en aljamas cuya dirección compartían con cadíes o en las que estos últimos no existían, el alamín contenía de forma individual ${ }^{43}$.

En cuanto a las tareas administrativas, sobre todo las que son de índole económico, los alamines destacaban por su papel como colectores de contribuciones y rentas de los señores y de su propia institución, arrendamiento de derechos, participación en el repartimiento de las cosechas de los mudéjares, evaluación alzada de las producción (alfarraçament), presencia y garante en las subastas y reparto de riego ${ }^{44}$. En este amplio marco de poder que realiza el alamín en la gestión económica de la aljama, por lo menos en bastantes ejemplos en territorio valenciano, muchas veces en relación y otras tantas en manifiesta oposición a

42. R.I. BuRns, L'Islam sota el croats..., pp. 143-146.

43. Febrer Romaguera, M. V., «La administración económica de las aljamas mudéjares valencianas..., pp. 267-275. Es el caso de muchas de las aljamas de la Marina (Denia, Sagra, Pop, Callosa, Alaguar, Guadalest, Ebo) el alamín compartía con el cadí las función judicial que, a juicio de M.V. Febrer, fue importante, sin embargo no podía suplantar a la jurisdicción del cadí, y sólo circunscribirse al cuidado de los intereses de los señores y de la propia aljama. Atribuciones judiciales que hacen participar a los alamines en las ejecuciones de sentencias decretadas por jueces superiores, tomando empares, penyores y caplleutes ante la conservación de los derechos de los señores o aljamas, llevar a cabo embargos y realizar actuaciones de tipo represivo y procesal. Ibidem, pp. 269-272.

44. Ibidem, p. 272-275, donde se recogen ejemplos de cada una de esta funciones administrativas en algunas aljamas valencianas. En el caso de las aljamas de la Gobernación de Orihuela (Orihuela, Elche, Crevillente, Alicante y Valle de Elda) $\mathrm{M}^{\mathrm{a}} \mathrm{T}$. Ferrer ha considerado al alamín como una figura importante, por lo menos en el caso de Elche. Sin embargo, los datos conocidos no conducen a saber con precisión la actuación de dicho cargo en tierras oriolanas. Por ejemplo de las aljamas de Orihuela y del valle Elda no hay mención del alamín y prevalecía la figura del cadí; Ferrer i MALlol, Mª T., Les aljames sarraines..., pp. 58-60, y 76-79 respectivamente. En cambio Elche hay alguna noticia de la existencia de una alamín en 1296, su participación en el reparto del riego de la huerta: Ibidem, p. 61; Febrer Romaguera, M.V., «La administración económica..., p. 273. En Crevillente también existe algún otro dato de la implicación de este individuo en el reparto de riego: Ibidem, p. 273. Y en Alicante si parece que el alamín tuvo una función importante ya que presidía la aljama y tenía competencia en justicia: Ferrer i Mallol, M ${ }^{\mathrm{a}}$.T., Les aljames sarraines..., p. 67. 
la función ejercida también por el mustaçaff, habría que situar el papel/función/ potestad que ejerce este individuo a la hora concertar acuerdos con mercaderes cristianos para dar salida a una parte de la producción de la institución que coordina y otra de su propia titularidad.

El reflejo de lo arriba expuesto se plasma en numerosos transacciones en la que participan los alamines y más propiamente los cuatro contratos que pasamos a describir ${ }^{45}$. A fines de agosto de 1318, Homar Apolopi, alamín de la aljama de Beniclet, concertó la venta de 200 quintales de uva pasa con Jaume Castellet, mercader de Valencia. Dicha producción procedía de la aljama en su mayor parte, 150 quintales, y una cantidad menor, 50 quintales, del alamín. Las obligaciones de una y otros eran muy precisas; Apolopi se comprometía a depositar en la playa de Albalat toda la cantidad de pasas durante el mes de octubre. Recibía por ello una cantidad de 10 sueldos y 4 dineros por cada quintal vendido a lo que habría que añadir otros 8 dineros por quintal por transportar desde la alquería hasta Albalat la mercancía ${ }^{46}$. Durante este año y precisamente en el mismo mes de septiembre se registran otras tres transacciones más de uva pasa por parte de las aljamas de la Marina Alta en las actas notariales, en dos de ellas interviniendo de nuevo los alamines y negociadas esta vez con mercaderes de Valencia y Barcelo-

45. Existen, además, otras referencia a la participación de los alamines en las transacciones como la venta que hizo Çahat Atzenete, sarraceno alamín de Picasent, a Arnau Andreu, arrocerio de Valencia, de una 390 cahíces que tenía en término de Ruzafa, a razón de 15 libras y que se destinarían al cultivo de dicho producto; A.R.V. P. Not, A. Lappart, No 10.408, (30-diciembre-1326). O el mismo y Abrafim Taraçoni, alamín de Buñol, quien junto a Domigo Aguilar, vecino de Valencia reconocían deber a Arnau de Peralada y Bernat de Camprodó, pañeros de Valencia, 126 sueldos por la compra de paños; A.R.V. P. Not, A. Lappart, № 2791, (24-abril-1317) Así como Açmet Almatarri, cadí de los lugares de la montaña («alcadus montanarum»), propiedad de Bernat de Sarrià, y Açmet Abennabil, alamín de Finestrat, Jahia Abenahech, alamín de Tarbena y Alí Amathmut, alamín de Beniardá, quienes reconocen deber a Pascual Estalella, vecino de Callosa, 7 cahíces de trigo a razón de 20 sueldos por una compra que el útlimo realizó: A.R.V. P. Not, A. Lappart, No 2758 (9-mayo-1330). También destacamos otros 7 cahices de trigo, a 19 sueldos la unidad, que vendieron Açmet Algizar y Juceff Alfaquí, alamines de Xelva y Chiva a Pere Arnau, carnicero de Valencia y le debían depositar en dicha ciudad el próximo agosto: A.R.V. P. Not, A. Lappart, nº 2758 (31-mayo-1330). U otros dos cahíces que compró Miquel Pere, esparterio de Valencia, a Jaffar, alamín de Chest por un valor de 18 sueldos y 10 dineros el cahíz: A.R.V. P. Not, A. Lappart, n 2758 (9-junio-1332). Por último, la actividad de la autoridades musulmanes de las aljamas del valle de Ayora, pertenecientes al señorío de Bernat de Sarrià, quienes como Alí Abenjaffar, cadí del citado valle y alamín de Xarafull, vendía la décima de la aljama de Cofrentes y una importante cantidad de madera a un vecino de Valencia, Bernat de Plano. Y la deuda que contraían este mismo individuo- Abenjaffar- junto con Mahomat Phabip, Axer Abendacxen, Mahomat Almaxfet, Alí Esquerdo y Hayut Algizari, alamines de Zarra, Palaciolos, Teresa, Xalanç y probablemente Cofrentes, quienes junto a Pascual Moya, notario de Ayora, reconocían deber a Jaume de Palma, vecino de Valencia, 100 libras por una cantidad de carne que Bernat de Sarrià había comprado a diversos carniceros valencianos. Las dos operaciones en A.R.V. P. Not, A. Lappart, nº 2758, (28-mayo-1330) y (9-junio-1330). En cuanto a los aspectos político-económicos del valle de Ayora es interesante: FERRER I MALLOL, $\mathrm{M}^{\mathrm{a}}$.T., «La carta de població dels sarraïns de la vall de Ayora (1328)», en Sharq al-Andalus, 3, 1986, pp. $81-94$.

46. A.R.V. P. Not. D. Claramunt, $\mathrm{N}^{0} 10.405$, (28, agosto, 1318). 
na que también son frecuentes en las operaciones ligados con las redes mercantiles exteriores. El 11 de septiembre de 1318, el alamín de los valles de Sagra y del Pop, Açmer Abençunqyher, junto con otros mudéjares de estas aljamas, acordaban con Jaume Picot, mercader de Valencia, la venta de 500 quintales de pasas que debían llevar al puerto de Denia durante los quince días siguientes a la firma del contrato. Los moros percibían una cantidad similar a la referida el contrato anterior, esto es, 10 sueldos por cada quintal ${ }^{47}$. Asimismo en este día se estipulan otras dos ventas más, lo significativo de estas últimas, además de responder a los mismos parámetros que las anteriores, es la participación de mercaderes que tienen una función destacada en el mercado valenciano (fletes de naves, constitución de sociedades mercantiles, transacciones de paños u operaciones crediticias con mercaderes florentinos $)^{48}$. Mahomat Abharrahit, alamín de los valles Jalón, y Çahat Açmer, sarraceno de este mismo lugar, concertaron con los hermanos Pere y Llop Ginestar, mercaderes de Valencia, la venta de otros 430 quintales de pasa a cambio de una cantidad de 8 sueldos y 5 dineros por cada unidad que le debían satisfacer con prontitud. A su vez, los mudéjares también recibían otros 6 sueldos por trasladar las pasas al puerto de Denia ${ }^{49}$. Por último, los moros de Alaquas, Mahomat Çamarro y Abdolazic Albayt, firmaban un acuerdo con los miembros de una sociedad mercantil, Bernat Pençal y Bernat Çavila, mercaderes de Valencia y Barcelona respectivamente, en la que les vendían 320 quintales de pasa a razón de 8 sueldos y 5 dineros la unidad. Una cantidad que se veía incrementada por los 10 dineros por quintal al llevar desde su aljama a Denia la citada mercancía ${ }^{50}$. Una vez depositado el producto en los embarcaderos de la Marina se producía la posterior distribución de éste por parte de un activo grupo mercantil que ya desde fines del Doscientos y sobre todo en la centuria posterior

47. A.R.V. P. Not. A. Lappart, $\mathrm{N}^{\circ}$ 2627, (11, septiembre, 1318). El estado del documento impide conocer si recibieron alguna cantidad por transportar la mercancía, práctica que era bastante habitual.

48. Los vínculos sociales y políticos de estos mercaderes, su participación en las diferentes actividades económicas así como sus estrategias sociales las hemos desarrollado en J.L Soler MiLla, Métodos comerciales y rutas mercantiles marítimas, cit; Idem, «Valencia y su dinamismo comercial: génesis y desarrollo de sociedades mercantiles durante la primera mitad del siglo XIV», en prensa. En cuanto al papel de los Ginestar en el comercio pañero: G. Romestan, «Els mercaders llenguadocians..., op. cit., J. Bordes GARCí, Desarrollo industrial textily artesanado en Valencia de la conquista a la crisis (1238-1350). Tesis Doctoral Inédita, Valencia, 2003. Algunas operaciones crediticias con mercaderes florentinos: C. Cuadrada., A. ORLANDI, «Ports, tràfics, vaixells, productes: italians i catalans a la Mediterrània baixmedieval», en Anuario de Estudios Medievales, 24 (1994), pp. 4-48.

49. A.R.V. P. Not. A. Lappart, $\mathrm{N}^{\circ} 2627$, (11, septiembre, 1318).

50. A.R.V. P. Not. A. Lappart, $\mathrm{N}^{\circ} 2627$, (11, septiembre, 1318). En las cuatro estipulaciones el precio del quintal de pasa oscila entre 8 y 5 dineros y 10 sueldos por quintal de pasas. No variaba mucho de la tarifa que se concertaba a fines de la baja Edad Media. Casi dos siglos después de las operaciones reseñadas, la cotización de este fruto basculaba entre 6 sueldos y 9 dineros y 11 sueldos y 3 dineros por quintal para los años 1493-1509 Guiral HadziIossif, J., Valencia, puerto mediterráneo..., p. 419, nota 96. 
dirigía su interés y capital para hacerse con esta producción ${ }^{51}$. A continuación se comercializaba en los mercados mediterráneos, puertos catalano-occitanos y en mayor volumen en la ruta norteafricana, muchas veces con previa escala en el mercado mallorquín o con parada de las nave insulares en tierras decá y dellà Xixona, a tenor de los nòlits conservados en los documentos valencianos ${ }^{52}$.

\section{CONCLUSIONES}

De este modo y a través de lo expuesto anteriormente podemos considerar que el binomio mercader-producción mudéjar queda favorablemente declinado al último factor. No obstante, hemos creído oportuno insertar ambos elementos para tratar de ofrecer una imagen más global del componente musulmán, bien humano o bien productivo, en un aspecto muy concreto pero a su vez claramente determinante de las relaciones económicas: los intercambios mercantiles.

Al final de todo el proceso, bien por el interés de los mercaderes valencianos por hacerse con mercancías de clara procedencia musulmana y sobre todo en su intención de desarrollar una estructura mercantil en los mercados norteafricanos donde estos productos - pasas y también higos, algarrobas, avellanas, almendras- tenía una recepción excepcional, el mayor beneficio recaló en los propios mercaderes que contaron con todos los mecanismos a su favor y supie-

51. Además de las estipulación aquí reseñadas, en el vasto mercado valenciano se producen numerosos intercambios de higos y pasas y se desarrollan sociedades mercantiles que concentran sus recursos en la distribución de estos productos como la compañía que constituyeron Guille Jordi y Pere de Lemena, mercaderes de Barcelona y Girona, con un capital de 220 libras para negociar con la venta de pasas en Colliure y Aigües Mortes durante los primeros meses de 1317.

52. Torró Abad, J., El naixement..., pp. 228-230, Cabezuelo Pliego, J.V., «Comercio y puertos de señorío..., en prensa, Soler Milla, J.L., Métodos comerciales..., en prensa; Idem, «La actividad comercial en la Gobernación..., en prensa, Idem, «Valencia y el Norte de África..., op. cit.. Tendencia que estas tierras mantendrán durante el Cuatrocientos constituyéndose en un centro exportador también frutos secos en el mercado atlántico; vid. Hinojosa Montalvo, J., «De Valencia a Portugal y Flandes. Relaciones durante la Edad Media», en Anales de la Universidad de Alicante. Historia Medieval, 1, Alicante (1982), pp. 163, (149-168), Cruselles Gómez, E., «Denia en el sistema de intercambios bajomedieval», en III Congrés d'Estudis de la Marina Alta, Alicante, 1992, p. 172 (171-178); Idem, Los mercaderes de Valencia ..., pp. 249-254; IGUAL LuIs, D., «Itinerarios comerciales en el espacio meridional mediterráneo de la Baja Edad Media», en XXVII Semana de Estudios Medievales de Estella: «Itinerarios medievales e identidad hispánica», Pamplona, 2001, pp. 130-131 (113-158). En cuanto a la función de las tierras meridionales valencianas como escala en los periplos de las naves mallorquinas: Sevillano Colom, F., «Mercaderes y Navegantes mallorquines (siglos XIII-XV)», en J. Mascaró Passarius (ed.), Historia de Mallorca, 1971, Palma de Mallorca, p. 572; Mª . D. López PÉrez, La Corona de Aragón y el Magreb..., p. 570-571 y más recientemente, Idem, «Mallorca y el Magreb en la Baja Edad Media», en C. TRILlo SAN José. (ed.), Relaciones entre el Mediterráneo cristiano y el norte de África en época medieval y moderna. Granada, 2004, p. 165 (87-226) y Soler Milla, J.L., «La actividad comercial..., 239-240; Idem, «Intercambiar y vincularse económicamente en el Mediterráneo Occidental: un ejemplo a través del estudio de las relaciones comerciales entre Valencia y Mallorca durante la primera mitad del siglo XIV», en Jiménez AlCÁzAr, J.F., Soler Milla, J.L, Actas del III Simposio Internacional de Jóvenes Medievalistas Lorca 2006, Lorca (Murcia), pp.187-189. 
ron acaparar la producción de las aljamas que ante estas actitudes y actividades no podían responder dado su sometimiento y debilidad política. La incapacidad de las aljamas para comercializar sus frutos en las redes exteriores al haberse visto desprovistas y carecer de medios y estructura que si comenzaba a tener el incipiente grupo mercantil valenciano, sobre todo por razones de índole política y económica, limitaron el desarrollo de estas instituciones que contemplaron cómo su producción, en algunos casos ciertamente importantes, era absorbida por las autoridades feudales en forma de impuestos, o bien progresivamente acaparada por los mercaderes de la capital, en su gran mayoría cristianos, a tenor de su notable rentabilidad en los mercados del Mediterráneo Occidental. 